upper part of the ionosphere by radio-wave sounding from heights well above that of the peak ionization.

Investigations of the characteristics of the troposphere continued to be conducted by staff of the Radio Research Station by several different methods. The micro-wave radio refractometer carried in an aircraft, as described in previous reports, has been used to record the gradient of refractive index at various heights: and in several cases these have been correlated with the existence of layer-type echoes observed by vertical-sounding radar technique. The process of the scattering of radio waves by discrete layers or other types of discontinuity in the troposphere has been studied by measuring the variations in direction of transmission of a narrow beam of waves. To some extent, the results have been related to the prevailing meteorological conditions, taking advantage of information, when available, obtained from radio-sonde ascents.

A programme of intornational intercomparison of reference standards for measuring power at microwave frequencies has been in progress for several years. A wire bolometer transfer standard for use at a frequency of about $9 \mathrm{Gc} / \mathrm{s}$, which had been calibrated by microcalorimeter reference standards in the United States and in Japan, was checked against a film bolometer standard developed at the Radio Research Station. The results were in agreement with the American and Japanese reference standards to within \pm 0.9 per cent. At a lower frequency of $300 \mathrm{Mc} / \mathrm{s}$, a coaxial transfer standard subrnitted by the National Bureau of Standards, Boulder Laboratories, was compared with two instruments at Slough: a coaxial thermionic diode and a thermistor milliwattmeter. The measurements made in the United States and United Kingdorn agreed to within 0.3 per cent; which is well within the limits of error assigned to any one of the reference standards. The various techniques now available in the United Kingdom make it possible to carry out measurements of power above a few milliwatts at froquencies up to $30 \mathrm{Gc} / \mathrm{s}$. Power measuremont at higher frequencies probably depends on the development of new techniques.

As in the caso of previous reports, appendixes give details of the Committees of the Radio Research Board, the staff of the Radio Research Station and the papers published by them during 1961 .

\title{
SATELLITE METEOROLOGY
}

QINCE the first observations commenced to be $\$$ received from Tiros 1 there has been much speculation concerning the optimum utilization of meteorological satellites in meteorological operations and research. In particular, it is reasonable to inquire whether the enthusiasm and novelty which these spectacular technical advancements have aroused will gradually fade away with the realization that, however spectacular they may be, their real value is limited, or whether the observations will represent a true potential for meteorological operations and research.

It has always been appreciated that the main practical value of the observations lies in the use which can be made of cloud picture mosaics in regions where the supply of weather reports from the normal station network is inadequate. This is especially so over the huge extent of the oceans of the globe, much of which is only sparsely threaded with ships' trading routes, assisted at a few strategic places by ocean weather stations. The identification of incipient, or even fully developod, tropical cyclones before they have been picked up by the conventional observational network represents an outstanding and much publicized example of the great value which cloud observations from satellites can be to national meteorological services charged with giving timely preventative warnings to communities likely to be affected by these devastating storms. But such occurrences are relatively rare in the spectrum of meteorological ovents, and it is hoped that more lasting and regular returns will be received from these expensive observations.

There are many less-obvious uses of observations from meteorological satellites. The photographs themselves can reveal the distribution of snow and ice-fields in addition to cloud cover. Photographs of snow-covered land masses can, for example, help to provide information about water resources. At night, when clouds are not properly visible, an approximate distribution of the cloud pattern may be obtained from infra-rod radiation measurements. Such radiation suffers little absorption during its passage through the atmosphere and enables an estimate to be made of the temperature of the radiating surface. Clouds are thus revealed as cold areas against the warmer background of the Earth's surface. The temperature pattern of the upper cloud surface may yiold an index of the contours of that surface.

Future developments may enable measurements to be made in the centimetre wave-length band which would identify precipitation areas and freezing-levels by radar techniques. It should also be possible for observations of lightning to be made, either by visible flashes or by sferics discharges. Finally, it has been suggested that the satellites might be used for global communications to relay pressure, temperature and wind data made by automatic weather stations in oceans and remote land areas.

The United Nations General Assembly has shown an awareness of the international aspects of the question in passing a resolution dealing with International Co-operation in the Peaceful Uses of Outer Space. A section of this resolution of December 1961 includes a request that the World Meteorological Organization should report to its member Governments on the appropriate organizational and financial arrangements: (1) to provide a greater knowledge of the basic physical forces affecting climato and the possibility of large-scale weather modifications; (2) to help members to make the utmost use of existing weather forecasting possibilities.

The report has now been prepared*; it lists several basic requirements to translate the potential of weather satellites into a working seheme.

There is first a need for an internationally coordinated plan to achieve agreed decisions concerning satellite orbits, types of observations to be made collection and dissemination of data and standardization of accuracies. The plan should provide for research on the use of the data received. The most

* W.MO Bulletin, 11, No. 3; July 196 
important recommendation in the report is no doubt the call for a 'world weather watch', a global meteorological observing and prediction system designed to avoid duplication of effort in the preparation of analysed charts and forecasts, yet providing all meteorological services with the basic data needed to carry out their responsibilities. The report also proposes that the scope and quality of both conventional and satellite observations should be improved and emphasizes that the latter supplement but do not supplant the former. Optimum results can be achieved by means of a combination of the wide scanning ability of the satellites with the capabilities of the usual vertical sounding instruments. Improvements should also be made to the communication facilities to permit the rapid trans- mission of a greatly increased volume of meteorological traffic throughout the world. The hope is expressed that the satellites themselves may serve as communication systems for this purpose.

The evaluation of the optimum utilization of meteorological satellites is an important issue that must be faced. The United Nations and its specialized agency, the World Meteorological Organization, have taken a big step forward. The working group which has been established to formulate an atmospheric sciences programme will keep the matter under active review until the World Meteorological Organization Congress constitutes an advisory committee at its fourth session in April 1963. There is a long road to tread before the full potential of meteorological satellites will come to fruition. A. H. GorDON

\section{FILARIASIS}

$\mathrm{D}$ URING the past few years, filariasis control has progressed to the point where it has become possible to look forward to the introduction of eradication campaigns like that organized by the World Health Organization for malaria. In contrast to the malaria programmes, however, the first line of attack would have to be mass chemotherapy, mainly because of the long life of the parasite in the human body. To keep transmission at a low enough level to ensure eradication, chemotherapy will have to be backed up by adequate vector control. This may not prove easy, since the culicine mosquitoes, the main vectors of filariasis, rapidly acquire resist. ance to the commonly used insecticides and since the habitats of some of the mosquitoes make it difficult to attack them by conventional methods.

The World Health Organization Expert Committeo on Filariasis has reviewed recent advances in the epidemiology of Wuchereria and Brugia infections and directed attention to the many problems on which research is still needed*. It is important to improve methods of identifying developing forms of filariæ in mosquitoes, so that carriers of animal filariæ should not be mistaken for vectors of the

* World Health Organization. Technical Report Series. No. 233 : Expert Committee on Filariasis (Wuchereria and Brugia Infections) H.M. Stationery Office, 1962). 2 Swiss franes ; $3 s .6 d . ; 0.60$ dollars. human infection. Expert taxonomic, $\theta$ cological and other studies are needed to establish the strains with the highest infective potential and the most effective means of destroying them. Rapid urbanization has enabled Culex fatigans to breed apace in some areas with only primitive sanitation, and the situation has been made worse where insecticide spraying campaigns for malaria eradication have eliminated competitors of this mosquito. The Committee recommends that, wherever possible, Culex fatigans should be attacked by improvements in sanitation aimed at suppressing man-made breeding sites.

Diethylcarbamazine appears to be still the most satisfactory drug available for mass chomotherapy, but a number of new compounds containing arsenic or antimony are at present under trial. Further research is needed to establish the best dosage schedule for diethylcarbamazine- one that, in order to ensure a high acceptability, combines effectiveness with ease of administration and relative freedom from side-effects.

Among the other subjects suggested for research. the Committee advocates studies on transmission and on the life-cycle of the parasite in relation to clinical manifestations, serological and immunological studies on filariasis, and an investigation of the effect of malaria eradication activities on the local epidemiology of filariasis.

\section{INHERITANCE IN BACTERIA}

\begin{abstract}
MONG the wide variety of research activities described in the report of the Governing Body of the Lister Institute of Preventive Medicine for $1962 *$, that of the investigations of the GuinessLister Unit into inheritance in bacteria is of particular interest. The Unit continued its investigation of inheritance in bacteria of the Salmonella (food poisoning and enteric fever) groups, using two different kinds of fertility factor to induce conjugation: the colicine factors, which determine the production of antibiotics called colicines, and the $F$ factor and some variants of it, transferred from Escherichia coli.
\end{abstract}

* The Lister Institute of Preventive Medicine. Report of the Governing Body 1962. Pp. 29. (London: The Lister Institute of Preventive Medicine, 1962).
S. Smith continued to map the chromosome of Salmonella typhimurium, obtaining conjugation (and hybridization) by the use of colicine factors col $I$ and col EI. Additional hereditary characters were introduced into the strains used, by the isolation of mutants unable to synthesize particular amino-acids, to ferment particular sugars or to produce the fraction of the polysaccharide component of the $O$ antigen factor 5. Many of these mutants were obtained by treating bacteria with the mutagen ethyl methane sulphonate. The genes regulating all the characters concerned were mapped in the single closed-loop linkage map already tentatively established. Dr. B. A. D. Stocker, E. Subbaiah, and E. Dubnau, using the same system, investigated the segregation of additional characters resulting from 